\title{
PERAN DUKUNGAN SOSIAL DAN STRATEGI COPING TERHADAP SELF EFFICACY PADA KORBAN CYBERBULLYING
}

\author{
Ahmad Wahyu Rasyidi ${ }^{1}$, Riana Sahrani ${ }^{2}$ \\ ${ }^{I}$ Magister Psikologi, Universitas Tarumanagara Jakarta \\ Email : ahmad.717171029@stu.untar.ac.id \\ ${ }^{2}$ Program Studi Fakultas Psikologi, Universitas Tarumanagara Jakarta \\ Email : rianas@fpsi.untar.ac.id
}

Masuk : 22-11-2019, revisi: 25-11-2019, diterima untuk diterbitkan : 26s-11-2019

\begin{abstract}
ABSTRAK
Perkembangan teknologi internet yang sangat pesat mendorong munculnya berbagai macam media sosial yang di gunakan oleh remaja. Berbagai dampak yang negatif yang nyata dan marak terjadi di media sosial adalah perundungan dengan memakai media internet dan media sosial, yang disebut dengan istilah cyberbullying. Tujuan penelitian ini adalah untuk mengetahui peran dukungan sosial dan strategi coping terhadap self-efficacy pada korban cyberbullying. Responden dalam penelitian ini sebanyak 204 orang dengan dengan pengambilan data secara convenience sampling. Hasil penelitian menunjukan bahwa terdapat peran negatif dan signifikan dari dukungan sosial terhadap self-efficacy $(\mathrm{t}=-3.15>-1.96)$. Selain itu hasil penelitian menunjukan bahwa tidak terdapat keterkaitan antara problem focus coping dengan self-efficacy. Namun, hasil penelitian menunjukan bahwa terdapat peran positif dan signifikan emotional focus coping terhadap self-efficacy $(t=2.16>1.96)$.
\end{abstract}

Kata Kunci: self-efficacy, dukungan sosial, strategi coping, cyberbullying

\section{ABSTRACT}

The development of internet technology is very fast to encourage the emergence of various kinds of social media consumed by teenagers. Various negative impacts that are real and widespread on social media is bullying on the internet or media social, called cyberbullying. The purpose of this study was to study the role of social support and coping strategy toward self-efficacy among cyberbullying victims. This study obtained 204 respondents by convenience sampling. The results showed a negative and significant role social support toward self-efficacy $(t=-$ $3.15>-1.96)$. In addition, the results of the study showed there is no connection between problem focus coping and self-efficacy. However, the research showed the positive and significant role emotional focus coping toward selfefficacy $(t=2.16>1.96)$.

Keywords: self-efficacy, social support, coping strategy, cyberbullying

\section{PENDAHULUAN}

\section{Latar Belakang}

Masa remaja yang merupakan salah satu fase paling sulit dan kritis dari rentang kehidupan membawa banyak tantangan. Remaja mengalami banyak perubahan kognitif, emosional, fisik dan sosial. Perubahan ini dapat menyebabkan peningkatan tingkat perilaku berisiko yang berpotensi berbahaya bagi individu dan stress (Bignol, 2018). Dengan perkembangan teknologi yang marak saat ini telah membuka gerbang informasi remaja di seluruh dunia untuk berinteraksi dengan orang lain. Perkembangan ini tentu memberikan kemudahan bagi setiap remaja untuk mendapatkan informasi mengenai semua hal sehingga terkadang tidak dikontrol dan melebihi batas yang seharusnya (Barus, 2019)

Korban cyberbullying mendapatkan beberapa macam perilaku diantaranya; korban mendapatkan kata-kata kasar dari pelaku, diancam, menyebarkan rumor hingga merusak pertemanan, membuka akun media sosial korban secara paksa, membagikan gambar tentang korban yang bertujuan untuk mempermalukan korban, mengucilkan korban dari media sosial hingga merekam korban ketika ia dipukuli oleh orang lain dan membagikannya di internet (Lohbeck \& Petermann 
dalam Willard, 2018). Dalam penelitian yang dilakukan oleh (Shemesh \&Heiman dalam Musharraf, 2018) individu yang mengalami cyberbullying mempunyai self-efficacy yang rendah dibandingkan orang-orang yang tidak mendapatkan cyberbullying di internet.

Korban cyberbullying mendapakan posting menyakitkan, memalukan serta mengacam dalam bentuk tulisan maupun gambar menggunakan internet, telepon genggam serta alat komunkasi lainnya melalui media sosial maupun media lainnya. (Storey \& Slaby, 2008). Dalam survei yang dikeluarkan oleh (Indikator, 2019) sosial media yang digunkakan oleh remaja di Indonesia yang mengalami cyberbullying diantara lain adalah (a) Whtasapp (77\%) (b) Facebook (43\%) (c) Youtube (28 \%) (d) Instagram (23\%) (e) Line (5\%) (f) Twitter (2\%) (g) Telegram (1\%). Sementara diluar penelitian di Amerika, Penggunaan media sosial juga digunakan oleh remaja yang mengalami bullying di internet beberapa diataranya adalah (a) Youtube sebanyak 85\%, (b) Instagram sebanyak 72\%, (c) Snapchat sebanyak 69\% (d) facebook sebanyak $51 \%$. (e) Twitter sebanyak 32\% (f) Tumblr sebanyak 9\% (Anderson \& Jiang, 2018). Reaksi Remaja yang mengalami bullying di internet berbagai macam di antaranya (a) meresepon bullying di internet $(65,8 \%)$ (b) bertemu secara langsung face to face sebanyak (35\%). (c) Mengindari untuk pergi kesekolah $(15,4 \%)$ (d) merespon dengan kekerasan fisik kepada pelaku cyberbullying $(4,5 \%)$ (Insight \& McAffe, 2012). Remaja yang mengalami bullying di internet mendapatkan lima jenis perlakuan, (a) name calling harassment (45.5\%), (b) rumors/gossip, (31.3\%), (c) menerima ancaman $(5.1 \%)$, (d) menerima konten-konten pornografi $(2.6 \%)$. (e) menerima aib mereka disebarkan di internet $(15,6 \%)$ (Triantoro \& Tentama, 2016).

Respon remaja dalam menghadapi bullying di internet beragam diantaranya (a) tidak menghiraukan perilaku bullying $(25,3 \%)$. (b) melawan kembali individu yang melakukan bullying terhadap mereka $(49,5 \%)$. (c) menceritakan kepada orang tua $(11,1 \%)$ (Triantoro \& Tentama, 2016). Salah satu kemampuan yang diperlukan pada remaja yang mendapatkan bullying di internet adalah Self-Efficacy yang dapat diartikan sebagai kepercayaan individu terhadap kemampuannya sendiri dalam memecahkan sebuah masalah (Bandura dalam Bignol, 2018). Bandura (1997) mengatakan bahwa self-efficacy merupakan keyakinan akan kemampuan individu untuk dapat mengorganisasi dan melaksanakan serangkaian tindakan yang dianggap perlu untuk mencapai suatu hasil yang diinginkan (Bandura dalam Anggraeni, Sahrani, Hastuti, 2017).

Dalam penelitian di Instanbul yang melibatkan siswa menengah pertama kelas 8 yang berjumlah 185 siswa, Self-Efficacy mempunyai peran yang signifikan terhadap korban cyberbullying. (Bignol, 2018). Dalam penelitian yang mengukur tinggi atau rendahnya Self-Efficacy pada korban cyberbullying dalam hal jenis kelamin, laki-laki mempunyai Self-Efficacy lebih tinggi dibandingkan perempuan ketika mendapatkan bullying di internet (Bignol, 2018). Selain Efikasi diri, faktor-faktor lain yang menyababkan cyberbullying terjadi adalah; kecerdasan sosial, kontrol orang tua yang rendah, pengawasan orangtua terhadap teknologi yang digunkan remaja serta dukungan sosial yang didapatkan remaja dari teman sebaya maupun orang lain (Underwood \& Ehrenreic, 2017)

Penelitian lainnya yang melibatkan 482 siswa yang 140 siswa diantanya adalah ADHD. Menghasilkan bahwa korban cyberbullying mempunyai kaitan dengan rendahnya Self-Efficacy dan minim dukungan sosial dari lingkungan. (Heiman, Shemesh, Eden, 2015). Dalam penelitian yang mengukur hubungan antara Self-Efficacy dan dukungan sosial dengan jumlah total 32 responden. Ditemukan bahwa tidak terdapat hubungan 0.378 ( $>0.05)$. antara Self-Efficacy dengan dukungan sosial (Ismarwati \& Rohmah, 2017). 
Dalam penelitian yang dilakukan untuk mengukur sumber dukungan sosial terhadap korban cyberbullying, sumber dukungan sosial yang seringkali didapatkan oleh korban berasal dari teman sementara dukungan orang tua maupun dukungan significant other tidak berperan (Bilgin \& Tas, 2018). Faktor yang mempengaruhi tinggi rendahnya bullying di internet pada korban adalah dukungan sosial. Karena seringkali korban mendapatkan tuntutan maupun tekanan dari kelompok. Tuntutan tersebut dapat berupa tuntutan normatif dan informatif (Worchel \& Cooper dalam Mawardah, 2014).

Sumber dukungan sosial yang didapatkan oleh korban bullying di internet ada bermacammacam. Diantaranya adalah (a) Teman sebaya (b) Orangtua (c) Guru. Rendahnya dukungan sosial juga turut menyumbangkan peran dalam bullying di internet (Ortega et al., 2016). Dalam penelitian yang dilakukan dengan mengukur persepsi korban cyberbullying remaja pada guru, ditemukan bahwa bullying di internet yang menceritakan pengalaman bullying yang ia alami di internet kepada guru mempunyai kecenderungan dukungan sosial disekolah (Simao et al., 2017). Dukungan sosial yang rendah disekolah dari guru, kondisi sekolah yang tidak kondusif serta transisi perpindahan siswa dari satu jenjang ke jenjang yang lebih tinggi juga menjandikan remaja mudah mendapatkan cyberbullying dari orang yang dikenalnya maupun tidak dikenalnya (Kowalski dalam Erreygers, 2018).

Remaja yang mengalami cyberbullying dan kurang mendapatkan dukungan sosial yang rendah dari orangtua dan guru juga berkorelasi dengan prestasi akademik yang rendah di sekolah (Lohbeck \& Petermann dalam Beran, 2018). Dalam penelitian yang dilakukan di Australia (Lohbeck \& Petermann dalam Lee, 2018) lain peer pressure dalam cyberbullying juga dapat mengakibatkan simtom depresi pada remaja. Faktor lainnya yang diasosiasikan dengan korban cyberbullying selain Self-Efficacy adalah strategi coping yang baik. Sehingga individu yang mengalami cyberbullying mempunyai perspektif dan dapat menempatkan diri secara positif (Ramirez, 2007).

Strategi Coping sebagai kemampuan mengubah kognitif atau perilaku secara konstan agar tuntutan eksternal maupun internal khususnya yang diperkirakan membebani dan melampaui kemampuan individu dapat melemah (Lazarus, 2007). Strategi Coping dapat dibagi menjadi dua macam antara lain emotion focus coping yang digunakan untuk mengatur respon emotional terhadap stres dan problem focus coping yaitu dengan mempelajari cara-cara atau keterampilanketerampilan yang baru (Smet, 1994). Dalam penelitian yang dilakukan untuk mengukur efektifitas coping strategies pada 22 siswa, hasilnya terdapat pengaruh antara problem focused coping dan emotion focused coping dalam hal pengelolaan stress pada korban cyberbullying (Bakhthiar \& Asriani, 2015). Dengan adanya perbedaan hasil penelitian berkaitan dengan variabel Coping Strategi dan dukungan sosial terhadap Self-Efficacy, maka dari itu peneliti tertarik untuk mengambil judul Peran Coping Strategi dan Dukungan Sosial terhadap SelfEfficacy pada korban cyberbullying.

\section{Rumusan Masalah}

Dari latar belakang yang di uraikan di atas, maka dapat di rumuskan yang menjadi masalah penelitian adalah sebagai berikut: "Apakah terdapat peran dukungan sosial dan coping stretegy terhadap self efficacy pada korban cyberbullying?" 


\section{METODE PENELITIAN}

\section{Partisipan dan Prosedur Penelitian}

Partisipan penelitian ini adalah para remaja yang pernah menjadi korban bullying di internet dengan usia 13-21 Tahun. Subjek berjenis kelamin laki-laki maupun perempuan, Tidak dibatasi ras, etinis, suku, agama dan lainnya. Subjek yang di teliti berjumlah 204 orang yang mengunakan kuesioner elektronik. Penelitian ini dilakukan dari tanggal 15 Mei sampai 30 Mei 2019 dengan menggunakan kuisioner elektronik. Peneliti menyebarkan di sosial media seperti Instagram, Facebook, Twitter, Whatsapp dan Line. Sebelum pengambilan data, peneliti menyiapkan instrumen penelitian yang diperlukan seperti kuisioner yang telah diuji validitas dengan cara tryout kuisioner dan peneliti juga melakukan expert judgement kepada tiga pakar. Peneliti mempersiapkan beberapa keperluan seperti surat pengantar, Memorandum of Agreement,informed consent, dan juga lembar kuesioner yang akan dibagikan pada partisipan. Kuesioner yang digunakan dalam penelitian ini terdiri dari butir-butir pernyataan.

\section{Pengukuran/Instrument Penelitian}

Alat ukur self efficacy maupun alat ukur coping strategy merupakan buatan peneliti sendiri. Alat ukur sudah di uji realibilitas maupun validitasnya. Selain itu dari variabel social support yang penulis menggunakan replikasi dari penelitian yang digunakan oleh (Yudisthira, 2017). Dengan nilai alpha Cronbach 0,826 .

\section{HASIL PENELITIAN DAN PEMBAHASAN}

Gambaran demografi partisipan penelitian ini pertama adalah berdasarkan jenis kelamin. Berdasarkan data yang diperoleh, jumlah paling sedikit adalah laki-laki sejumlah 66 orang (32.4\%) dan partisipan terbanyak adalah perempuan sebanyak 138 orang $(67.6 \%)$.

Tabel 1

Gambaran Partisipan Berdasarkan Jenis Kelamin

\begin{tabular}{ccc}
\hline & & \\
Jenis Kelamin & Frekuensi & Persentase \\
\hline Laki-laki & 66 & 32.4 \\
Perempuan & 138 & 67.6 \\
\hline Total & 204 & 100.0 \\
\hline
\end{tabular}

Gambaran demografi partisipan penelitian ini berikutnya adalah berdasarkan frekuensi menggunakan internet. Berdasarkan data yang diperoleh, jumlah paling sedikit adalah partisipan yang menggunakan internet 23-24 jam sejumlah 2 orang (1\%) dan partisipan terbanyak adalah yang menggunakan internet dengan frekuensi 5-6 jam sebanyak 53 orang (26\%).

Tabel 2

Gambaran Partisipan Berdasarkan Orang Terdekat

\begin{tabular}{ccc}
\hline Orang Terdekat & Frekuensi & Persentase \\
\hline Ayah & 11 & 5.4 \\
Ibu & 93 & 45.6 \\
Saudara & 12 & 5.9 \\
Teman & 76 & 37.3 \\
Pacar & 12 & 5.9 \\
\hline Total & 204 & 100.0 \\
\hline
\end{tabular}


Gambaran demografi partisipan penelitian ini berikutnya adalah berdasarkan domisili. Berdasarkan data yang diperoleh, jumlah paling sedikit adalah partisipan yang memiliki domisili di Jakarta Pusat sejumlah 6 orang $(2.9 \%)$ dan partisipan terbanyak adalah yang berdomisili di Tangerang sebanyak 45 orang $(22.1 \%)$.

Tabel 3

Gambaran Partisipan Berdasarkan Kategori Bullying

\begin{tabular}{lcc}
\hline Kategori Bullying & Frekuensi & Persentase \\
\hline Flamming & 36 & 17.6 \\
Online Harrasment & 13 & 6.4 \\
Cyberstalking & 5 & 2.5 \\
Denigration & 61 & 29.9 \\
Impersonation & 3 & 1.5 \\
Outing & 5 & 2.5 \\
Trickery & 13 & 6.4 \\
Exclusion & 68 & 33.3 \\
\hline Total & 204 & 100.0 \\
\hline
\end{tabular}

\section{Analisis Data Utama}

Pada bagian hasil penelitian ini akan dibahas mengenai uji hipotesis pada variabel penelitian. Berdasarkan hasil pengujian hipotesis yang dilakukan dengan menggunakan SEM, maka diperoleh hasil variabel-variabel eksogen (variabel independen) penelitian ada yang memiliki peran positif dan signifikan terhadap variabel endogen (variabel dependen) pada penelitian ini namun adapula yang memiliki peran negatif dan signifikan serta ada variabel yang tidak memiliki peran signifikan. Keseluruhan hasil tersebut dapat dilihat dari output nilai $\mathrm{t}$ pada pengujian SEM dengan menggunakan LISREL 8.80 yang menunjukkan nilai uji t hitung > 1.96.

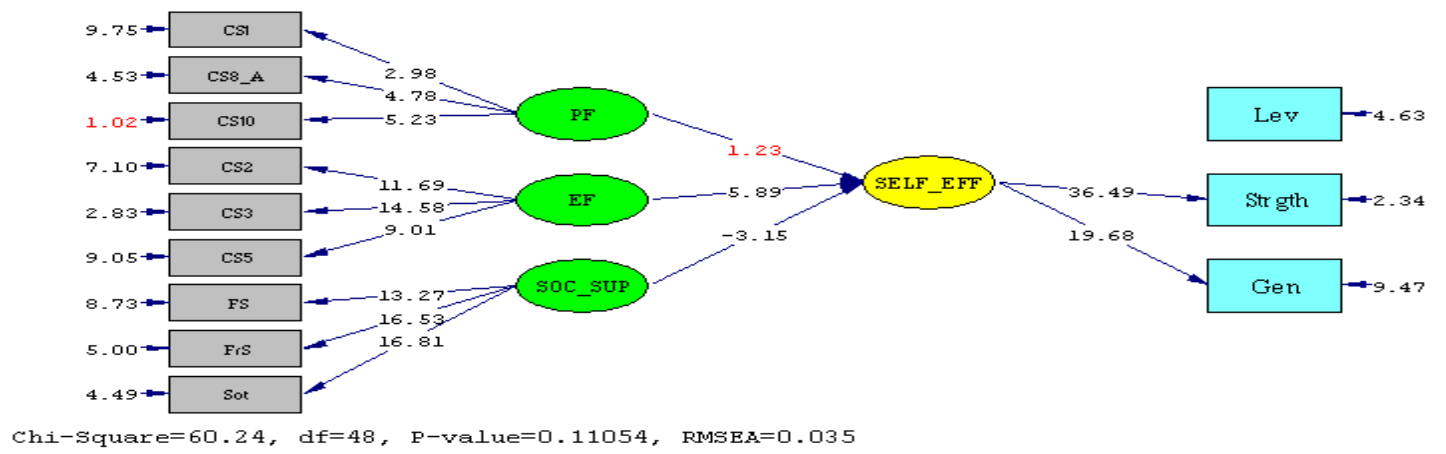

Gambar 4. Hasil Output T Values Pada Pengujian Hipotesis

Berdasarkan output $t$ values dapat dilihat bahwa dari variabel emotional focus memberikan peran positif signifikan kepada variabel self-efficacy yang dapat dilihat dengan nilai $\mathrm{t}=5.89>1.96$ jadi dengan demikian memiliki peran positif dan signifikan. Selanjutnya variabel social support memberikan peran signifikan kepada variabel self-efficacy yang dapat dilihat dengan nilai $\mathrm{t}=$ $3.15>-1.96$ jadi dengan demikian memiliki peran negatif dan signifikan. Berdasarkan nilai $\mathrm{t}$ dapat dilihat bahwa peran paling besar yang memengaruhi self-efficacy adalah emotional focus. 
Sedangkan untuk problem focus tidak memiliki peran signifikan karena nilai $\mathrm{t}=1.23<1.96$ jadi dengan demikian memiliki tidak ada peran signifikan.

Selanjutnya untuk melihat nilai koefisien determinasi $\left(\mathrm{R}^{2}\right)$ beserta persamaan regresinya maka dapat dilihat pada bagian output dari lisrel sebagai berikut:

SELF_EFF $=0.086 * \mathrm{PF}+0.43 * \mathrm{EF}-0.22 * \mathrm{SOC} \_\mathrm{SUP}$, Errorvar. $=0.69, \mathrm{R}^{2}=0.31$
(0.070)
(0.073) (0.069)
1.23
5.89
$-3.15$
$(0.078)$
8.83

Dengan demikian maka jika dilihat dari nilai $\mathrm{R}^{2}=0.31$ menunjukkan bahwa peran dari variabel independen terhadap dependen adalah sebesar $31 \%$ sedangkan sisanya diprediksi dari variabel lain di luar penelitian ini.

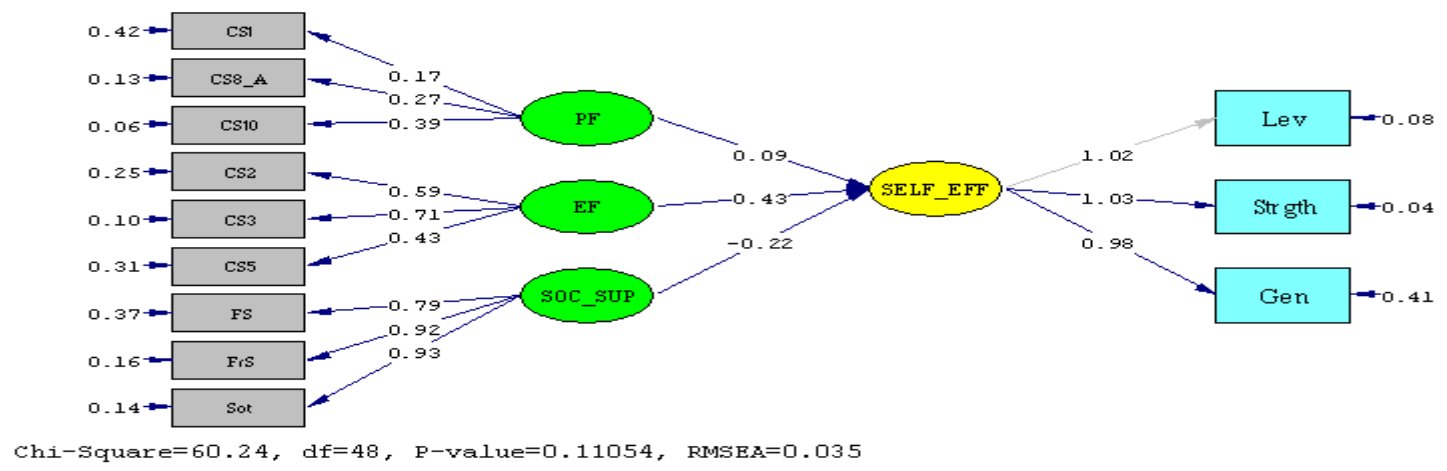

Gambar 5. Hasil Output Estimates Pada Pengujian Hipotesis

\section{KESIMPULAN DAN SARAN}

Hasil penelitian menunjukan terdapat peran yang siginifikan antara cybervictimization dengan Berdasarkan analisis data yang telah dilakukan mengenai peran social support dan coping strategy terhadap self-efficacy maka diperoleh hasil ternyata terdapat peran positif dan signifikan emotional focus terhadap self-efficacy. Kemudian untuk social support terdapat peran negatif dan signifikan. Hal ini menunjukkan bahwa semakin tinggi emotional focus maka semakin tinggi self efficacy. Namun demikian semakin tinggi social support yang dimiliki partisipan penelitian maka semakin rendah pula self efficacy. Sementara hasil lainnya juga menunjukkan dalam penelitian ini bahwa problem focus tidak memiliki peran signifikan terhadap self-efficacy.

Hasil temuan pada penelitian ini telah sejalan dengan penelitian yang dilakukan oleh Donkoh dan Yelkpieri (2011) yang juga menemukan hasil yang sama bahwa problem focus sebagai strategi coping tidak memiliki peran signifikan dibandingkan dengan emotional focus. Hasil ini sekaligus menunjukkan bahwa untuk meningkatkan self efficacy yang dibutuhkan adalah strategi emotional focus. Selain itu hasil penelitian ini juga sejalan dengan penelitian Sari (2010) yang menemukan hasil bahwa remaja yang menjadi partisipan penelitiannya juga lebih dominan untuk menggunakan emotional focus untuk meningkatkan self efficacy nya. Emotional focus merupakan strategi coping dengan melakukan motivasi pada diri sendiri walaupun tidak menyelesaikan sumber permasalahan yang ada.

Hasil selanjutnya adalah secara umum social support memiliki peran negatif dan signifikan terhadap self efficacy, namun demikian kita dilakukan pengujian data tambahan diperoleh hasil peran negatif dan signifikan diperoleh dari dimensi dukungan family sedangkan untuk significant others ditemukan peran positif dan signifikan. Dengan demikian family justru akan menurunkan 
self-efficacy sedangkan untuk significant others (diluar keluarga serta teman) merupakan faktor dukungan yang meningkatkan self-efficacy. Untuk dukungan dari teman tidak berperan signifikan terhadap self-efficacy.

Dengan adanya hasil ini maka penelitian ini melengkapi penelitian yang dilakukan oleh Ismarwati dan Rohmah (2017) yang menemukan hasil adanya hubungan signifikan antara social support dengan self-efficacy. Dengan adanya hasil penelitian ini, maka selain adanya hubungan ternyata social support juga memiliki peran signifikan ada yang untuk meningkatkan selfefficacy yaitu dukungan dari significant others dan ada yang menurunkan self-efficacy yaitu dukungan dari family.

Hasil selanjutnya adalah berdasarkan pengujian data tambahan dengan melakukan uji perbedaan self-efficacy ditinjau dari jenis kelamin yang memeroleh hasil bahwa tidak adanya perbedaan signifikan self-efficacy ditinjau dari jenis kelamin. Namun demikian jika dilihat dari nilai rerata dari laki-laki sedikit lebih tinggi dibandingkan dengan perempuan, dimana hasil ini sama dengan yang ditemukan oleh Bignol (2018) bahwa laki-laki mempunyai Self-Efficacy lebih tinggi dibandingkan perempuan ketika mendapatkan bullying di internet.

Partisipan yang mengisi kuisioner kebanyakan berada di self efficacy level generality yaitu Perasaan mampu yang dimiliki seseorang sebagai tindakan yang dimilikinya untuk menguasai tugas dalam kondisi tertentu. Self-efficacy juga berbeda pada generalisasi artinya individu menilai keyakinan mereka berfungsi di berbagai kegiatan tertentu. Penilaian ini terkait pada aktivitas dan konteks situasi yang mengungkapkan pola dan tingkatan umum dari keyakinan orang terhadap keberhasilan mereka. Keyakinan diri yang paling mendasar adalah orang yang berada disekitarnya dan mengatur hidup mereka (Feist dalam Bandura, 2017). Dalam hal ini, para responden seringkali melihat tokoh politik maupun tokoh agama yang mempunyai self efficacy baik yang dijadikan sebagai role model.

Selain itu, masalaah-masalah lain yang tidak tercantum dalam kuisioner dalam hal-hal yang dialami adalah para korban mendapatkan cyberbullying karena mereka mempunyai preferensi seksual dari kebanyakan orang pada umumnya. Hal ini dibuktikan dengan para responden yang mengatakan bahwa mereka merasa dikucilkan dan diejek karena mereka berbeda preferensi seksual dengan kebanyakan orang.

Keterikatan guru dalam mengurangi korban cyberbullying dalam penelitian ini tidak ada. Terlihat dalam penelian yang dilakukan peneliti bahwa tidak ada responden yang mendapatkan dukungan sosial dari guru. Bahkan dalam cerita salah satu responden, guru juga ikut melakukan cyberbullying kepada korban.

Penelitian ini memiliki beberapa keterbatasan yaitu dari teknik sampling yang digunakan yaitu convenience sampling akhirnya menjadikan pemilihan partisipan adalah hanya berdasarkan kemudahan yaitu karena bertemu dan sesuai dengan karakteristik partisipan penelitian. Dengan demikian, di masa depan penelitian juga dapat diarahkan pada teknik probability sampling agar hasil penelitian dapat digeneralisir.

Dalam penelitian ini masih terdapat kekurangan dan kelemahan. Oleh karena itu, dalam penelitian selanjutnya yang mungkin akan dilakukan oleh para peneliti lain disarankan untuk menggunakan penelitian trianggulasi dengan menggabungkan teknik kuantitatif dan kualitatif sehingga peneliti dapat mengumpulkan data-data yang diperlukan dengan lebih akurat dan kaya. 
Dengan demikian, hasil penelitian bisa lebih baik. Penelitian yang di lakukan oleh peneliti responden cenderung masih sedikit sehingga untuk penelitian berikutnya diharapkan responden yang diteiti jumlah lebih besar guna mendapatkan analisis statistik yang lebih kuat.

Penelitian ini dapat memberikan manfaat untuk terutama dalam psikologi terutama dalam bidang psikologi pendidikan. Hasil penelitian ini memberikan bukti empiris bahwa dalam pengembangan self-efficacy penting untuk ditumbuhkan pada korban bullying dengan penggunaan emotional focus strategi untuk coping terhadap permasalahan yang dialami nya. Selain itu diperlukan dukungan dari significant others untuk meningkatkan self-efficacy agar dapat menyelesaikan permasalahan yang dialami para korban bullying. Selain itu literatur mengenai cyberbullying masih sangat terbatas di Indonesia, sehingga cyberbullying masih perlu diteliti lebih luas. Tidak hanya dalam bentuk penelitian dalam bentuk kuantitatif maupun kualitiatif tapi juga dalam bentuk intervensi sehingga memberikan pengaruh langsung pada korban-korban cyberbullying maupun yang bukan korban.

Saran yang diberikan kepada para siswa yang menjadi responden dalam penelitian ini untuk dapat terus menggunakan segala daya upaya yang dimiliki supaya selalu dapat berjuang terus mengembangkan dirinya dengan baik. Mengasah kemampuan diri dan meningkatkan selfefficacy akan membantu mahasiswa mengembangkan dirinya dengan baik dan menggunakan emotional focus untuk memotivasi diri sendiri bahwa diri sendiri mampu untuk mengatasi segala permasalahan yang ada sehingga keluar dari permasalahan yang ditimbulkan dari bullying. Remaja yang mengalami cyberbullying juga dapat memblokir akun pelaku cyberbullying serta menyimpan screenshot sebagai bukti telah mendapatkan cyberbullying, selanjutnya korban dapat melaporkanya orangtua maupun kepada pihak yang berwajib.

Saran yang diberikan kepada sekolah agar menciptakan suasana sekolah yang nyaman, dengan cara mengedukasi siswa-siswa dengan psikoedukasi yang berupa roleplay dan tidak hanya dengan ceramah. Sehingga memudahkan remaja untuk mengetahui strategi yang tepat ketika mendapatkan bullying di internet bahkan dapat mencegah terjadinya bullying di internet pada remaja. Sekolah juga melakukan koordinasi dari kepala sekolah kepada guru BK untuk membuat peraturan dalam sekolah untuk mengurangi cyberbullying. Selain itu, kuirikulum sekolah juga dapat dimasukan materi yang berhubungan dengan regulasi emosi, empati serta kepemimpinan dalam mata pelajaran kewarganegaraan atau mata pelajaran terkait harapannya akan menekan angka cyberbullying di sekolah.

Saran bagi pemerintah daerah setempat, untuk membuat aturan atau undang-undang tentang prevensi maupun penanggulangan pada cyberbullying. Sehingga bisa menjadi efek jera bagi pelaku dan juga korban mendapatkan rasa aman karena pemerintah mempunyai aturan mengenai aturan-aturan tentang cyberbullying. Walaupun sekarang sudang ada undang-undang ITE, namun undang-undang tersebut hanya mengatur menghukum atau menlindung individu yang telah berusia 17 tahun keatas. Sehingga perlu undang-undang tambahan atau revisi undang-undang untuk memperkuat peraturan yang sudah ada. Saran selanjutnya diberikan bagi orang-orang yang berada di sekitar partisipan untuk senantiasa membantu korban bullying agar keluar dari permasalahan yang dihadapinya. Motivasi dari orang di sekitarnya akan meningkatkan selfefficacy di dalam diri korban bullying sehingga para korban tersebut akan mampu menyelesaikan permasalahan di dalam hidupnya.

Orang terdekat juga dapat mencari tahu penyebab korban mendapatkan cyberbullying. Selain itu korban cyberbullying juga dapat melakukan aktifitas yang berhubungan dengan self-reflection, 
sebagai orang terdekat kita juga dapat menanyakan serta mengidetifikasi apa yang mereka pikir dan rasakan dan juga apa yang orang lain rasakan sehingga juga dapat mengebangkan rasa self awareness dan juga regulasi diri serta empati kepada orang lain. Mencontohkan role model yang mempunyai self efficacy baik dalam menghadapi cyberbullying dalam kehidupan sehari-hari juga membantu dan mengambarkan pada korban agar dapat mendapatkan kemampuan efikasi diri yang baik. Untuk keluarga dari korban bullying diharapkan tidak memberikan tuntutan kepada korban bullying dikarenakan hal itu justru akan menurunkan self-efficacy mereka. Pendampingan serta keterbukaan untuk menerima keluh kesah dari para korban bullying akan membantu mereka untuk keluar dari permasalahan yang sedang mereka hadapi hasil dari bullying yang diterima dan dapat hidup dengan sejahtera kembali.

\section{Ucapan Terima Kasih}

Kami mengucapkan terima kasih kepada semua pihak yang telah membantu terlaksananya penelitian dan mencapai publikasi ini, khususnya kepada para partisipan penelitian.

\section{REFERENSI}

Anggraeni, M. Sahrani, R. Hastuti, R. (2017) Perbedaan Prestasi Belajar Matematika Ditinjau dari Self-Efficacy dan Mathematic Anxiety Siswa SMP di Depok. Jurnal Muara. (1) 1. 201-209

Barus, R. (2019) Korban Cyberbullying, Siapakah?. Jurnal Simbolika. (5) 1. 35-43

Biglin, T. Tas, I. (2018). Effects of Perceived Social Support and Psychological Resilience on Social Media Addiction among University Students. Journal of Educational Research 6(4). 751-758

Bignol, T. Y. (2018) Determining the Predictors of Self-Efficacy and Cyberbullying. International Journal of Higher Education. 7 (2). 138-143.

Dalgleish, J (2010). Cyberbullying: Experiences, Impacts And Coping Strategies As Described. 29 (2).

Feist, J \& Feist, G. J. ( 2008). Theories Of Personality. New York: Mcgraww Hill.

Heinan, T. Shemesh,D. O. (2013) Cyberbullying Experience and Gender Differences Among Adolescents in Different Educational Settings. Journal of Learning Disabilities.

Canty-Mitchell, J. \& Zimet, G.D. (2000). Psychometric properties of the Multidimensional Scale of Perceived Social Support in urban adolescents. American Journal of Community Psychology, 28, 391-400.

Kowalski, R. M., Giumetti, G. W., Schroeder, A. N., Lattanner. M.R. (2014) Bullying in the Digital Age: A Critical Review and Meta-Analysis of Cyberbullying Research Among Youth. American Psychology Association. 1-65

Lohbeck, A. Petermann, F. (2018) Cyberbullying: An increasing challenge for schools. School Psychology International Journal. 33(5). 467-47

Mawardah, M, Adiyanti, M. G. (2014) Regulasi Emosi dan Kelompok Teman Sebaya Pelaku Cyberbullying. Jurnal Psikologi 41(1).

Musharraf, S. (2018) Development and Validation of ICT Self-Efficacy Scale: Exploring the Relationship with Cyberbullying and Victimization. International journal of environmental research and public health. 1-13

Ortega, R (2012) Bullying and cyberbullying: Overlapping and predictive value of the cooccurrence. Psicothema, 24, 608-613.

Papalia, D. E., Olds, S.W., \& Feldman, R.D. (2009). Human development $11^{\text {th }}$ ed New York: McGraw-Hill.

Rasyidi, A, W. (2016) Hubungan Kecerdasan emosi dan coping stress terhadap resiliensi pada korban cyberbullying (Bachelor Thesis, Universitas Tarumanagara, Jakarta, Indonesia) 
Santrock, J. (2014). Adolescence. $15^{\text {th }}$ ed. New York: McGraw

Simao, A. M. (2017) Cyberbullying: The hidden side of college students. Computers in Human Behavior 43.167-182

Storey, K., Slaby, R., Adler, M., Minotti, J., \& Katz, R. (2008). Eyes on Bullying Toolkit. Diunduh pada 3 Juni , 2009, dari http://www.eyesonbullying.org/pdfs/toolkit.pdf

Subrahmanyam, K., Greenfield, P. (2008) Online Communication and Adolescent Relationships. The Future of Children journal 18(1). 119-46

Underwood, M. K., Ehrenreich, S. E. (2017) The Power and the Pain of Adolescents' Digital Communication: Cyber Victimization and the Perils of Lurking. American Psychological Association. 72, (2), 144-158

Yelkpieri, D. Donkoh, K. (2011) Coping With Stress: Strategies Adopted by Students at the Winneba Campus of University of Education. David Publishing. 290-299.

Yudisthira, S. (2018) Peran social support, academic burnout, self-efficacy, self esteem terhadap academic engagement dengan burnout sebagai variable mediator pada mahasiswa kedokteran (Master Thesis, Universitas Tarumanagara, Jakarta, Indonesia).

Zimet, G.D., Dahlem, N.W., Zimet, S.G. \& Farley, G.K. (1988). The Multidimensional Scale of Perceived Social Support. Journal of Personality Assessment, 52, 30-41.

Zimet, G.D., Powell, S.S., Farley, G.K., Werkman, S. \& Berkoff, K.A. (1990). Psychometric characteristics of the Multidimensional Scale of Perceived Social Support. Journal of Personality Assessment, 55, 610-17. 